\title{
X COLÓQUIO IBÉRICO DE GEOGRAFIA
}

VIRGÍNIA HENRIQUES ${ }^{1}$

PATRÍCIA PEDRo-RÊGO ${ }^{1}$

O X Colóquio Ibérico de Geografia subordinado ao tema "A Geografia Ibérica no Contexto Europeu" decorreu na Universidade de Évora, entre 22 e 24 de Setembro de 2005.

Este encontro ibérico realiza-se desde 1979, de três em três anos, alternadamente em Espanha e Portugal, numa organização conjunta da Asociación de Geógrafos Españoles e da Associação Portuguesa de Geógrafos, constituindo o principal encontro de reflexão e debate dos temas mais relevantes da Geografia Peninsular.

A escolha do tema do X Colóquio Ibérico resultou dos novos desafios colocados às regiões de Portugal e Espanha face ao recente alargamento da União Europeia. A Comissão Organizadora, ciente da necessidade de reflexão nesta matéria por parte da comunidade geográfica ibérica, estruturou o Colóquio em cinco Eixos Temáticos:
A. Novas estratégias e reorganização territorial numa Europa alargada;
B. Desafios para a multifuncionalidade da paisagem;
C. As cidades ibéricas entre o marketing urbano e as estratégias de bem-estar;
D. A geografia física da Península Ibérica, novos contributos;
E. Análise espacial e modelação geográfica.

As sessões temáticas decorreram nos dias 22 e 23 de Setembro e foram intercaladas por conferências e mesas redondas. $\mathrm{O}$ dia 24 foi dedicado a duas visitas de estudo, uma ao Empreendimento de Alqueva e outra à Região Transfronteiriça. Todas as actividades foram coordenadas por especialistas de várias universidades e instituições.

O Colóquio contou com 294 participantes dos quais 226 de Portugal, 63 de Espanha, 2 do Japão, e 3 de outras nacionalidades (Alemanha, Holanda e México), pertencentes a diferentes instituições (quadro I).

$\mathrm{Na}$ abertura dos trabalhos do Colóquio participaram o Professor João Ferrão, Secretário de Estado do Ordenamento do Território e das Cidades, o Professor Diogo Figueiredo, Vice-Reitor da Universidade de Évora, o Professor Ricardo Mendez, Presidente da Asociación de Geógrafos Españoles, o Professor Mário Vale, Presidente da Associação

1 Membros da Comissão Organizadora do Colóquio. Departamento de Geociências da Universidade de Évora, Rua Romão Ramalho 59. Évora.7000-671. E-mail virginia@uevora.pt e patrego@uevora.pt 
Quadro I - Proveniência dos participantes

Table 1 - Participant affiliation

\begin{tabular}{lcr}
\hline \multicolumn{1}{c}{ Instituições } & $\begin{array}{c}\text { N. } \mathbf{0}^{\mathbf{0}} \text { de } \\
\text { participantes }\end{array}$ & $\mathbf{( \% )}$ \\
\hline Universidades & 192 & 65,3 \\
Escolas de Ensino Básico e Secundário & 21 & 7,1 \\
Institutos Politécnicos & 16 & 5,4 \\
Associações Profissionais de Geógrafos & 8 & 2,7 \\
Organismos do Ministério da Educação e outros & 4 & 1,4 \\
Comissões de Coordenação, Delegações Regionais e Câmaras Municipais & 4 & 1,4 \\
Associações de Municípios e Associações de Desenvolvimento Local & 3 & 0,1 \\
Empresas Privadas & 4 & 1,4 \\
Sem instituição declarada & 42 & 14,3 \\
\hline
\end{tabular}

Portuguesa de Geógrafos e a Professora Emília Sande Lemos, Presidente da Associação de Professores de Geografia.

Para além das comunicações, o Colóquio integrou duas conferências e duas mesas redondas. No primeiro dia de trabalhos a conferência inaugural foi proferida pela Professora Maria Dolores Garcia Ramón, da Universidade Autónoma de Barcelona, intitulada Viajeras Europeas en el Mundo Árabe: una Mirada desde la Geografia Postcolonial (Gertrude Bell 1868-1926). O segundo dia de trabalhos iniciou-se com a conferência da responsabilidade do Professor Willem Vos da Universidade de Wageningen (Holanda), intitulada The Uniqueness of Iberian Landscapes within Mediterranean Europe. Ao início da tarde realizou-se uma mesa redonda dedicada ao tema "A Geografia e o Planeamento do Território". Nesta mesa redonda foram intervenientes o Professor Oriol Nello i Colon da Generalitát de Catalunya e a Professora Margarida Pereira da Universidade Nova de Lisboa. Os trabalhos foram coordenados pela Professora Teresa Barata Salgueiro, da Universidade de Lisboa. Ao fim da tarde realizou-se a última mesa redonda subordinada ao tema "Jovens Geógrafos. Progressos Científicos e Perspectivas Profissionais", da responsabilidade dos Professores João Sarmento, da Universidade do Minho, e Florêncio Zoido, da Universidade de Sevilha, que moderou a Sessão. Nesta mesa redonda participaram ainda o Professor Sérgio Claudino, da Universidade de Lisboa, os Professores López Lara e Miranda Bonilla, da Universidade de Sevilha, e o Professor João Ramires Pimenta, da Universidade do Porto.

Durante o Colóquio foram apresentadas 108 comunicações distribuídas pelos vários eixos temáticos e seguidas de debate amplamente participado.

O eixo temático A. Novas estratégias e reorganização territorial numa Europa alargada contou com a coordenação científica dos Professores Joan Nogué, da Universidade de Girona, e José Alberto Rio Fernandes, da Universidade do Porto. O eixo foi estruturado de acordo com os seguintes temas: A ideia de Europa; A dimensão territorial da Europa alargada; Novas estratégias de desenvolvimento territorial. Nesta temática foram apresentadas 17 comunicações.

O eixo temático B. Desafios para a multifuncionalidade da paisagem teve orientação científica dos Professores Rafael Mata, da Universidade Autónoma de Madrid, e Teresa Pinto Correia, da Universidade de Évora. As linhas de trabalho para este tema privilegiaram: $\mathrm{O}$ conhecimento da diversidade paisagística e suas multifuncionalidades; As transformações das actividades produtivas, em particular nas áreas rurais; Os valores da paisagem na gestão das áreas periurbanas; Os valores da paisagem nas ini- 
ciativas e políticas de desenvolvimento territorial e turístico; A análise e avaliação das políticas públicas para a conservação, gestão e recuperação das múltiplas funções da paisagem; A participação pública nas iniciativas de ordenamento e gestão da paisagem. Neste eixo foram apresentadas 24 comunicações.

$\mathrm{O}$ eixo temático C. As cidades ibéricas entre o marketing urbano e as estratégias de bem-estar com coordenação científica a cargo dos Professores Victor Fernández Salinas, da Universidade de Sevilha, e Maria Lucinda Fonseca, da Universidade de Lisboa, reuniu comunicações em torno de três temas fundamentais: A cidade ibérica, realidades e transformações estruturais impostas, estimuladas ou entorpecidas pelo papel de Espanha e Portugal na nova ordem global; Natureza e cultura como definidoras da identidade urbana ibérica; Cidadãos nas cidades ibéricas? Nesta temática foram apresentadas 33 comunicações.

O eixo temático D. A geografia física da Península Ibérica - novos contributos, coordenado cientificamente pelos Professores Júlio Muñoz, da Universidade Complutense de Madrid, e Lúcio Cunha, da Universidade de Coimbra, centrou-se nos temas: Análise, balanço e valorização da produção científica recente dos centros de investigação geográfica de Portugal e Espanha (organização morfo-estrutural, geomorfologia, bioclimatologia, hidrologia e paisagens naturais); Novas perspectivas de estudo de algum dos componentes do meio ou enquadrados em linhas de investigação com ideias críticas sobre componentes físicos ou das paisagens da Península; Novas perspectivas de aplicação de conceitos, métodos e técnicas no campo da planificação dos territórios peninsulares (recursos naturais, riscos naturais e impactes ambientais). Nestes temas foram apresentadas 24 comunicações.

O eixo temático E. Análise espacial e modelação geográfica com coordenação científica dos Professores Emílio Chuvieco, da Universidade de Alcalá de Henares, e José Tenedório, da Universidade Nova de Lisboa, privilegiou a apresentação de trabalhos orientados pelos tópicos: Modelação e simulação de fenómenos e processos espaciais; Identificação e análise de estruturas espaço-temporais; Análise espacial e representação geográfica; Detecção remota e análise geográfica; Aplicações Internet. Neste eixo foram apresentadas 10 comunicações.

No último dia de trabalhos realizaram-se as duas visitas de estudo com cerca de 70 participantes. Uma ao Empreendimento de Alqueva, organizada pelos Professores José Manuel Simões, da Universidade de Lisboa, e Teresa Pinto Correia, da Universidade de Évora, apresentou o Empreendimento de Fins Múltiplos de Alqueva e as Unidades de Paisagem de Campos de Reguengos e de Albufeira do Alqueva. A outra visita, com destino à Região Transfronteiriça, foi organizada pelas Professoras Inmaculada Caravaca e Rocio Silva, da Universidade de Sevilha, Isabel Margarida André, da Universidade de Lisboa, e Patrícia Pedro-Rêgo, da Universidade de Évora. Esta visita intitulada De Serpa a Almonaster la Real-Culturas e Paisagens de Fronteira privilegiou quer as questões da instabilidade histórica desta fronteira terrestre e o papel aí assumido pelas elites locais, quer a diversidade natural e humana da sierra de Huelva no contexto da sierra Morena.

A importância do Colóquio ficou demonstrada pelo interesse suscitado ao longo dos trabalhos e comprovada pela qualidade e pelo número das comunicações, mesas redondas e conferências proferidas. Os resultados dos trabalhos foram editados num livro de resumos com 280 páginas e num pequeno guia de campo com 43 páginas. O texto integral das comunicações foi posteriormente editado em formato digital. 